\title{
Inhibitory and Emotional Control Deficits as Predictors of Symptoms of Problem Behaviors among Juvenile Delinquents
}

\author{
Abdul Rahman Ahmad Badayai, Rozainee Khairudin, Wan Shahrazad Wan Sulaiman
}

\begin{abstract}
Executive dysfunction of inhibitory and emotional control deficits has not gained attention as a predictor in previous research on problem behaviors. Thus, this study examined inhibitory and emotional control deficits as predictors of symptoms of problem behaviors. There were 404 young offenders with various crimes such as stealing, substance use, rape, homicide, gang fights, and early sexual relation/pregnancy and out of control behavior participated in the study. Behavior Rating Instrument of Executive Function-Self Report (BRIEF-SR) and Achenbach System of Empirical Behavior Assessment (ASEBA-YSR) were employed, respectively. The results showed there was a significant relationships between inhibitory and emotional control deficits with both symptoms of problem behaviours; rule-breaking behavior and aggressive behavior. Moreover, based on regression weights, inhibitory control deficit was the best predictor of attention problems and aggressive behavior. On the contrary, an emotional control deficit was the best predictor of both symptoms of problem behaviors. In conclusion, the executive function plays a significant role in problem behaviors among juvenile delinquents. Thus early prevention based on both inhibitory and emotional controls component must be considered in three different settings such as family, school, and community. Thorough consideration in developing and inserting these two executive function components also are much needed in an educational setting as it is where adolescents spend much of the time.
\end{abstract}

Index Terms: inhibition, emotion, problem behavior, delinquency.

\section{INTRODUCTION}

Executive function is a set of higher-order cognitive processes, emotional, and motivational skills expressed in individual action and emotions [1]. The executive function includes different domains and processes such as goal formulation, inhibitory and emotional control, attention, pattern recognition, planning and implementation, self-regulation and evaluation, and flexibility [2]. The primary roles of executive functions are to regulate the

Revised Manuscript Received on September 25, 2019

Abdul Rahman Ahmad Badayai, Centre of Human and Societal Wellbeing, Faculty of Social Sciences and Humanities, The National University of Malaysia, Bangi Selangor, Malaysia.

Rozainee Khairudin, Centre of Human and Societal Wellbeing, Faculty of Social Sciences and Humanities, The National University of Malaysia, Bangi Selangor, Malaysia.

Wan Shahrazad Wan Sulaiman, Centre of Human and Societal Wellbeing, Faculty of Social Sciences and Humanities, The National University of Malaysia, Bangi Selangor, Malaysia. cognitive and emotion, and also adjustment of social behavior in the immediate environment where they develop [3]. However, impairments in any of the executive function features would lead to aggressive and impulsive behavioral patterns [4]. Additionally, the impairments in executive function are also associated with other psychiatric disorders especially the childhood-onset [4], [1], such as CD, ADHD, autism, physical aggression, and substance abuse [5]. Furthermore, Mullane, Corkum, Klein, McLaughlin, and Lawrence; Schoemaker, Bunte, Wiebe, Espy, Deković, and Matthys also claimed that the impairments of executive function associated with reduced adaptive behavior in ADHD, ODD, and CD [6],[7]. They also tend to defy and rebel any accepted guidelines and criteria at home, school, and in the community [8].

Furthermore, Van Goozen, Cohen-Kettenis,Snoek, Matthys, Swaab-Barneveld, \& Van Engeland, stated that children who suffer from ODD and CD have problems of emotional and motivational regulations [9]. The finding has been confirmed by Raaijmakers et al. that defects in the executive function, mainly inhibitory and emotional deficits, correlated with ODD, ADHD, and CD [10]. On the contrary, the study by Qian, Shuai, Cao, Chan, and Wang mentioned that adolescent with ODD and CD have no difficulty in their executive function [11]. However, this finding would somehow controvert with the existing literature on deficits in executive function leads to the different expression of symptoms of behaviors in conduct problems.

Hence, Blair \& Razza claimed that certain dissimilarities and variances of executive function are noticeable in healthy and normal youth, whereby the executive function is usually associated with other critical developmental consequences and trajectories[12]. These include learning readiness and social adaptation in the adulthood stage. Further, elements in the executive function, such as inhibitory and emotional control as well as external social interactions and situational challenges should have been taken into account as they are attributable to the emergence of conduct problems faced by adolescents [13].

A more detailed differentiation of executive dysfunctions in these conduct problems or problem behaviors are needed to be addressed critically as at present there are only a few studies on executive function have been conducted in children and adolescents with conduct problems [2] and also there is no agreement among researchers on the topic of executive 
function differences in the symptoms of behaviors in conduct problems. Thus, from the above research, it is believed that knowing the association between the executive function and symptoms of problems behaviors is very important, especially at youth age, since at this stage some aggressive behaviors may be prevented and proper intervention can be placed accordingly.

Therefore, the primary objective of this research was to study the inhibitory and emotional controls as predictors on the symptoms of problem behaviors among juvenile delinquents. Following that, three hypotheses were developed accordingly. 1. There is a significant relationship between inhibitory control deficit and symptoms of problem behaviors, 2. There is a significant relationship between emotional control deficit and symptoms of problem behaviors, and 3. Inhibitory and emotional control deficits significantly predicted symptoms of problem behaviors.

\section{METHODOLOGY}

\section{A. Research Design}

A cross-sectional design was used in this research. In order to support the research design, a correlational study was employed accordingly. A total number of 404 delinquents ranging from 13-18 year old participated in this study. The delinquents were from various institutions in Malaysia; Tunas Bakti school (272 respondents), Henry Gurney school (112 respondents), and Kajang prison (20 respondents). All delinquents in this study were earlier convicted with several crimes such as homicide, drug abuse, stealing, rape, gang fights, out of control behaviors and early sexual intercourse/pregnancy. Stratified random sampling was used in the research to ensure all respondents were eligible to be involved in the study. The unequal sample size of each stratum from the stratified sampling was required to determine the population size of the stratum [14]. Therefore, different sampling fractions of conduct problems cases for the research purpose.

\section{B. Instruments}

\section{Behavior Rating Inventory of Executive Function-Self Report (BRIEF-SR)}

The Behavior Rating Inventory of Executive Function-Self Report (BRIEF-SR) is an assessment of executive function behaviors for children and adolescents ages 5-18 [15]. It consists of 86 items. It has moderate to good reliability, with high test-retest reliability (rs - .88 for teachers, .82 for parents), internal consistency (alphas .80 - .98), and moderate correlations between parent and teacher ratings ( $r$ - .32 - .34). The assessment is also useful for evaluating children with a variety of disorders and disabilities including learning disabilities, Tourette syndrome, traumatic brain injury, pervasive developmental disorders, high functioning autism, low birth weight [15].

\section{Achenbach System of Empirical Behavior Assessment-Youth Self Report (ASEBA-YSR)}

The Child Behavior Checklist-Youth Self Report (CBCL-YSR) is an assessment to rate a child's competencies and problem behaviors [16]. It consists of 140 items. The CBCL construct measured several domains, such as Aggression, Hyperactivity, Bullying, Conduct Problems, Defiance, and Violence. There are high reports on the psychometric information on the CBCL; test-retest value is 0.95 to 1.00 , inter-rater reliability value is 0.93 to 0.96 , and internal consistency value is 0.78 to 0.97 [16].

\section{RESULTS AND DISCUSSION}

Hypothesis 1: There is a significant relationship between inhibitory control deficit and symptoms of problem behaviors.

Hypothesis 2: There is a significant relationship between emotional control deficit and symptoms of problem behaviors.

Based on table 1, a Pearson product-moment correlation coefficient was analyzed to assess the relationship between executive function and symptoms of problem behaviors. Table 1 showed there was a significant positive correlation between inhibitory and rule-breaking behavior ( $\mathrm{r}$ $=0.50, \mathrm{p}<0.01)$, and aggressive behavior $(\mathrm{r}$ $=0.58, \mathrm{p}<0.01)$. Moreover, there was also a significant positive correlation between emotional control with rule-breaking behavior $(\mathrm{r}=0.28, \mathrm{p}$ $<0.01)$, and aggressive behavior $(\mathrm{r}=0.44, \mathrm{p}$ $<$ 0.01). Overall, there were significant positive correlations between inhibitory, emotional control, and rule-breaking behavior and aggressive behavior. Thus, it indicated that respondents with higher scores in both inhibitory and emotional control deficits were more likely to exhibit rule-breaking behavior and aggressive behavior. Therefore, hypotheses 1 and 2 are accepted.

Moreover, according to the correlational results, delinquent adolescents who exhibit behavioral disinhibition are more likely to express other symptoms of behaviors such as social problems, thought problems, attention problem, rule-breaking behavior, and aggressive behavior. They consequently display some deficits in apparent executive function and abilities governed by healthy adolescents.

Besides, when a delinquent adolescent becomes frustrated and 
out of control, they may not effectively use the executive function strategies and schemes properly because of the disinhibition ability for doing so. These could be that children and adolescent, especially delinquent adolescents, are not being able to adequately regulate their behavioral and emotional control [17]. Furthermore, it is necessary to understand that different age group would lead to different results due to a different level of cognitive ability and capacity. Thus, Espy, Sheffield, Wiebe, Clark, and Moehr reported that in order to assess EF, age-appropriateness should be differentiated from impaired behaviors in delinquent adolescents [18].

Table 1: Results of correlation between inhibitory and emotional control deficits with symptoms of

\begin{tabular}{lcc} 
& problem behaviors & \\
\hline Variables & Rule-Breaking Behavior & Aggressive Behavior \\
\hline $\begin{array}{l}\text { Inhibitory Control } \\
\text { Deficit }\end{array}$ & $0.50^{*}$ & $0.58^{*}$ \\
$\begin{array}{l}\text { Emotional Control } \\
\text { Deficit }\end{array}$ & $0.28^{*}$ & $0.44^{*}$ \\
$* \mathrm{p}<0.01$ & &
\end{tabular}

While table 2 shows the inter-correlation matrix between both inhibitory and emotional controls deficits with symptoms of problem behaviors in adolescence. Based on the inter-correlation results, it is indicated significant relationships between all variables at $\mathrm{p}<0.01$.

Table 2: Inter-correlation matrix of executive dysfunction (inhibitory and emotional controls) and \begin{tabular}{lllll}
\multicolumn{5}{c}{ symptoms of problem behaviors } \\
\hline Variables & 1 & 2 & 3 & 4 \\
\hline 1. & Inhibitory & - & &
\end{tabular}

2. EmoControl $0.46^{* *}$

3. RuleBreakBeh $0.50^{* *} \quad 0.28^{* *}$

$\begin{array}{lll}\text { 4. AggressiveBeh } 0.58 * * & 0.44 * * & 0.73 * *\end{array}$

${ }^{*} \mathrm{p}<0.01$

Hypothesis 3: Inhibitory and emotional control deficits significantly predicted symptoms of problem behaviors.

Multiple regression analyses were conducted to examine the role of inhibitory and emotional control deficits as predictors towards rule-breaking behavior. Table 3 summarizes the descriptive statistics and inferential results. The multiple regression model with all two predictors produced $\mathrm{R}^{2}=.252$, $\mathrm{F}(2,400)=67.206, \mathrm{p}<.001$. As can be seen in Table 3, inhibitory control had significant positive regression weights, indicating respondents with higher scores on this scale were predicted to have a greater rule-breaking behavior problem, after controlling for other variables in the model. However, emotional control did not contribute to the multiple regression models.

Table 3: Summary of regression analysis of inhibitory and emotional control deficits and rule-breaking behavior

\begin{tabular}{lcccc}
\hline Variables & Mean & Std. & \multicolumn{3}{c}{ Multiple Regression Weights } \\
& & & b & $\beta$ \\
\hline Inhibitory & 19.97 & 3.54 & $.684 *$ & .469
\end{tabular}

Control

Emotional

Control

17.87

3.67

.090

.064

*p<.001

Multiple regression analyses were conducted to examine the role of executive function as predictors towards aggressive behavior. Table 4 summarizes the descriptive statistics and inferential results. The multiple regression model with all two predictors produced $\mathrm{R}^{2}=.369, \mathrm{~F}(2,400)=117.179, \mathrm{p}<$ .001 . As can be seen in Table 4 , inhibitory control and emotional control showed significant positive regression weights. Thus, indicating respondents with higher scores on these scales were predicted to have a higher aggressive behavior problem, after controlling for the other variables in the model. Overall, it was only explained $36.9 \%$ of the variation in inhibitory control and emotional control.

$\begin{aligned} & \text { Table 4: Summary of regression analysis of inhibitory and emotional control deficits and aggressive } \\
& \text { behavior }\end{aligned}$
\begin{tabular}{lcccc}
\hline Variables & Mean & Std. & $\begin{array}{c}\text { Multiple Regression Weights } \\
\text { b }\end{array}$ & $\beta$ \\
\hline $\begin{array}{l}\text { Inhibitory } \\
\text { Control }\end{array}$ & 19.97 & 3.54 & $.789^{*}$ & .475 \\
$\begin{array}{l}\text { Emotional } \\
\text { Control }\end{array}$ & 17.87 & 3.67 & $.352 *$ & .219 \\
\hline *p $<001$ & & & & \\
\hline
\end{tabular}

According to Cole, Michel, and Teti emotions are both context-appropriate and socially acceptable for a given situation [19]. Therefore, emotional displays are typically judged by cultural, social norms, and traditional context surrounding that guide one's affective display [19]. The emotion dysregulation may have resulted from either difficulty in modulating emotional reaction in response to one's social rules and environmental demands or lack of knowledge regarding affective display rules. Therefore, delinquent adolescents do not consider vigorous social rules and cues. However, they appear more socially de-regulated. Even, some studies indicated that young children and adolescents with disruptive behavior disorders have more emotional problems when they present deficits in their executive function [20].

It somehow strongly supports the existing literature that conduct problem adolescents are more likely to exhibit inhibitory and emotional control deficits as well as a high tendency to display aggressive behavior [21]. The deficits in emotional control and inhibitory could be the leading factors of conduct problem behaviors to occur.

Furthermore, the results raise the question of whether these domains of symptoms of behavior are demonstrated in conduct problem behaviors among delinquent offenders across ages. Risk-taking behaviors or conduct problems are complex, multi-faceted behaviors. They cannot be seen as a single construct. Different individuals involved in conduct problems would display various symptoms of behaviors. Blaise and Weber also claimed that risk-taking is domain-specific, and individuals are often not consistent in risk-taking tendencies across different situations [21].

Overall, the results 
corresponded with a growing body of research that some deficits partially in their executive functions, namely inhibitory and emotional controls, could cause adolescents' engagement in conduct problem. The symptoms of behavior that significantly affected executive function were attention problems and aggressive behaviors. The findings support the hypothesis that adolescents with less developed executive function or deficit are prone to involve in conduct problems as compared to adolescents with more developed executive function.

The results subsequently have a significant impact on the social community and educational policy making. Amendment on social and educational policy could have led to a healthier and enhancing the existing social and education policies. Since the executive function; inhibitory and emotional controls are the best predictors rule breaking behavior and aggressive behavior, this could be better to include inhibitory and emotional controls module as necessary components among adolescents in school. If only they were trained as early as possible, there could be fewer problem behaviors and another juvenile delinquency was reported especially in school. Furthermore, teachers, counselors, and school psychologists may be trained professionally on how to conduct, use, and implement the module of inhibitory and emotional control among adolescents. However, though it sounds easy to implementing in the social and educational settings, it might involve some financial expenditure. School and social community should take into consideration of the implementation of inhibitory and emotional controls skills development in the youth program in the future. Inserting these skills would enhance children and youth capacity and capability in regulating and directing towards sounded behaviors.

\section{CONCLUSION}

Conduct problem and other problem behaviors might be explained by both inhibitory and emotional control deficits concerning the expression of symptoms of problem behaviors among adolescents in their immediate live and intact environment. It is adolescents' deficit of inhibitory and emotional controls capacity that puts them in danger in engaging in risky and possibly harmful behaviors such as homicide, smoking, unprotected sex, gang fights, out of control behaviors, steals, and drug use. In other words, adolescents themselves have the capacity to realize and understand the risky situations in a similar way as adults. Instead, it is their vulnerability for heightened inhibitory and emotional control that places them into risk. Furthermore, an early intervention program could be useful when working with children and adolescents with conduct problems. An inhibitory and emotion-based intervention and treatment that focuses on the ability to identify skills necessary to tolerate ones affects an individual's knowledge and awareness about inhibitory and emotional control. If adolescents are more conscious and responsive to their inhibitory and emotional control, they could become competent enough to manage and solve their problematic behaviors in their environment at large.

\section{ACKNOWLEDGMENT}

Authors would like to show the gratitude to CRIM UKM for the research grant GGPM-2018-026. This research was fully supported by the above mentioned research grant, as without the grant, it was very impossible to complete this research.

\section{REFERENCES}

[1] Séguin, J. R., \& Zelazo, P. D. (2005). Executive function in early physical aggression. In R. E. Tremblay, W. W. Hartup, \& J. Archer (Eds.) Developmental origins of aggression (pp. 307-329). New York Guilford.

[2] Senn, T. E., Espy, K. A., \& Kaufmann, P. M. (2004). Using path analysis to understand executive function organization in preschool children. Developmental Neuropsychology, 26(1), 445-464 http://dx.doi.org/10.1207/s15326942dn2601_5

[3] Mattison, R. E., \& Mayes, S. D. (2012). Relationships between learning disability, executive function, and psychopathology in children with ADHD. Journal of Attention Disorders, 16(2), 138-146. http://dx.doi.org/10.1177/1087054710380188

[4] Wicks-Nelson, R., \& Israel, A.C. (2009). Abnormal child and adolescent psychology. (7th Ed.).Pearson Education: New Jersey.

[5] Willcutt, E. G., Doyle, A. E., Nigg, J. T., Faraone, S. V., \& Pennington, B. F. (2005). A meta-analytic review of the executive function theory of ADHD. Biological Psychiatry, 57, 1336-1346.

[6] Mullane, J. C., Corkum, P. V., Klein, R. M., McLaughlin, E. N., \& Lawrence, M. A. (2011). Alerting, orienting, and executive attention in children with ADHD. Journal of Attention Disorders, 15(4), 310-320.http://dx.doi.org/10.1177/1087054710366384

[7] Schoemaker, K., Bunte, T., Wiebe, S. A., Espy, K. A., Deković, M., \& Matthys, W. (2012). Executive function deficits in preschool children with ADHD and DBD. Journal of Child Psychology and Psychiatry, 53(2), 111-119. http://dx.doi.org/10.1111/j.1469-7610.2011.02468.x

[8] American Psychiatric Association. (2013). Diagnostic and statistical manual of mental disorders: DSM 5 (5th ed.). Washington, DC: iGroup Press.

[9] Van Goozen, S. H. M., Cohen-Kettenis, P. T., Snoek, H., Matthys, W., Swaab-Barneveld, H., \& Van Engeland, H. (2004). Executive functioning in children: A comparison of hospitalized ODD and ODD/ ADHD children and normal controls. Journal of Child

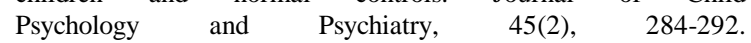
http://dx.doi.org/10.1111/j.1469-7610.2004.00220.

[10] Raaijmakers, M.A.J., Smidts, D.P., Sergeant, J.A., Maassen, G.H., Posthumus, J.A., Engeland, H., \& Matthys, W. (2008). Executive functions in preschool children with aggressive behavior: Impairments in inhibitory control. Journal of Abnormal Child Psychology, 36(7), 1097-1107. http://dx.doi.org/10.1007/s10802-008-9235-7

[11] Qian, Y., Shuai, L., Cao, Q., Chan, R. C. K., \& Wang, Y. (2010). Do executive function deficits differentiate between children with Attention Deficit Hyperactivity Disorder (ADHD) and ADHD - comorbid with Oppositional Defiant Disorder? A cross-cultural study using performance-based tests and the Behavior Rating Inventory of Executive Function. The Clinical Neuropsychologist, 24(5), 793-810. http://dx.doi.org/10.1080/13854041003749342

[12] Blair, C., \& Razza, R.A. (2007). Relating effortful control, executive function, and false belief understanding to emerging math and literacy ability in kindergarten. Child Development, 78, 647-663.

[13] Araujo, E.A., Jané-Ballabriga, M., Bonillo, A., \& Capdevilla, C. (2014) Executive function deficits and symptoms of disruptive behaviour disorders in preschool children. Universitas Psychologica, 13(4), xxx-Xxx. https:// dx.doi.org/10.11144/Javeriana.UPSY13-4.efds

[14] Saunders, M., Lewis, P., \& Thornhill, A. (2012). Research methods for business students. (6th ed). Pearson Education Limited. 
[15] Guy, S.C., Isquith, P.K., \& Gioia, G.A. (2004). Behavior Rating Inventory of Executive Function-Self Report Version Professional Manual. Florida: PAR.

[16] Achenbach, T.M., \& Rescorla, L.A. (2001). Manual for the ASEBA School-Age Forms \& Profiles. Burlington, VT: University of Vermont, Research Center for Children, Youth, \& Families.

\section{AUTHORS PROFILE}

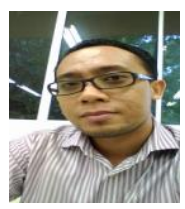

Abdul Rahman Ahmad Badayai Dr. Abdul Rahman Ahmad Badayai is a senior lecturer at Center of Human and Societal Well-Being, Faculty of Social Sciences and Humanities, The National Univeristy of Malaysia, Bangi Selangor, Malaysia. He received his Doctor of Philosophy in Psychology from The National University of Malaysia. His field of specialization is developmental psychology. Among his research interests are application of developmental psychology in infant and preschool assessment (prevention and intervention), at-risk youth prevention and intervention (bullying, early sexual behavior, substance use/misuse/abuse, violence and aggression, suicide, and school dropout), children and youth developmental assets, mental health prevention and intervention, sexual and gender-based violence. He has published his works in various journals; Journal Psychology Malaysia (JPM), Akademika, Journal of Social Sciences and Humanities (e-bangi), American Journal of Applied Psychology, International Journal of Psychology, and Journal of Education and Social Sciences.

Rozainee Khairudin Dr. Rozainee Khairudin is an associate professor at Center of Human and Societal Well-Being, Faculty of Social Sciences and Humanities, Universiti Kebangsaan Malaysia, Malaysia. She received her Doctoral degree and Masters of Science degree in Cognitive Science at University of Birmingham, United Kingdom. Her Bachelor degree is in Psychology from Univeristy of Reading, United Kingdom. Her research interests include mind-set, false memory, and effects of emotion on cognition.

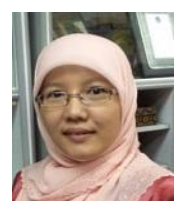

Wan Shahrazad Wan Sulaiman Dr. Wan Shahrazad Wan Sulaiman is an associate professor at Center of Human and Societal Well-Being, Faculty of Social Sciences and Humanities, Universiti Kebangsaan Malaysia, Malaysia. She received her Doctor of Philosophy in Psychology from International Islamic University Malaysia. Her field of specialization is psychometrics. Among her research interests are application of psychological tests, adaptation and standardization of psychological tests among prisoners for parole evaluation, psychological profile of drug addicts, personality profile of adolescents and juvenile delinquents, and assessment of critical thinking ability among university students. She has published her works in Journal Psychology Malaysia, Akademika, Pertanika Journal of Social Sciences and Humanities, World Applied Sciences Journal, American Journal of Applied Science and several other journals. 